\title{
Laboratory study on the relationship between soilmass deformation and water seepage in North China
}

\author{
Xiu Yan Wang $\cdot$ Jiang Chen $\cdot$ Lin Sun • \\ Shuang Ping Han $\cdot$ Yu Hong Fei $\cdot$ Jin Zhe Wang • \\ Chang Li Liu $\cdot$ Yun Zhang
}

Received: 4 April 2010/Accepted: 25 March 2011/Published online: 23 April 2011

(C) The Author(s) 2011. This article is published with open access at Springerlink.com

\begin{abstract}
The study on the relationship between the soilmass deformation and water seepage under certain stress in North China was conducted through combined tests of the consolidation deformation and water seepage. The results showed that the actual deformation of the clay soil under stress is greater than the deformation induced by the seepage. On average, the deformation induced by seepage was about $60 \%$ of the actual clay deformation under stress. The actual deformation of sandy soil, however, is less than the deformation induced by seepage. On average, the seepage-induced deformation was approximately $125 \%$ of the actual sandy soil deformation. These results indicated that the sandy soil did not have complete plasticity. Clay had the highest amount of water seepage and deformation, while silty soil, calcareous highly cemented clayed soil and sandy soil had less water seepage and deformation. The underlying mechanisms were also discussed. The results of this study contribute to the understanding of land subsidence mechanism and rough estimation of groundwater exploitation.
\end{abstract}

Keywords Clayey soil - Deformation amount - Seepage deformation - Effective stress - North China

\section{Introduction}

North China is in the temperate semi-arid, semi-humid climate zone and the average evaporation is much greater

X. Y. Wang $(\bowtie) \cdot$ J. Chen $\cdot$ L. Sun $\cdot$ S. P. Han ·

Y. H. Fei - J. Z. Wang - C. L. Liu · Y. Zhang

Institute of Hydrogeology and Environmental Geology, Chinese

Academy of Geological Sciences, Shijiazhuang 050061, China

e-mail: Wxiuyan9948@163.com than the precipitation. Although it belongs to Haihe River, Luanhe River and Yellow River basins, where several dozens of rivers and streams are distributed, most rivers have dried up and only a few rivers flow for a short time in flood season because of the decrease of rainfall and the interception of the upstream dams. Therefore, this region is seriously short of surface water. Shallow water is mostly saline, brackish and polluted (Hu 2004) and the reserves are limited. Thus, deep groundwater is the only water resource supply for the production, living and economic development in North China. With the development of the economy, the demand for water is increasing, and the depth of groundwater exploitation is also greater. For example, in Shijiazhuang City of Hebei Province close to the pediment rainfall recharge area of Taihang Mountains, the depth of exploitation wells reached $70 \mathrm{~m}$ from $20 \mathrm{~m}$ during the period 1960-2005 and the depth of exploitation wells in Huanghua was 330, 350 and $600 \mathrm{~m}$, respectively, in 1976, 1984 and 2001. Therefore, it leads to the determination of how much groundwater is available and how long groundwater exploitation may last.

In the process of land subsidence caused by deep groundwater exploitation, the seepage from soilmass deformation has become an important part of exploitable groundwater resource, although seepage from the soilmass deformation is not the traditional recharge water. In other words, seepage water is produced by the exploitation at the cost of environmental damage. With the continuous study of geology, other components of groundwater resources are gradually made clear, whereas the seepage water from the clay soil is still unclear, which is worthy of further study.

Perhaps for the purpose of simplifying the calculation model in the equilibrium calculation of groundwater exploitation, some researchers believed that the settlement of clayey soil is equivalent to the amount of seepage water, 
or the amount of seepage water is replaced by the amount of land subsidence (Gallardo et al. 2009). Based on this view, some researchers held that seepage water from the compaction of clay soil accounted for about $41 \%$ of total exploitation of deep groundwater, and others held that about $80 \%$ of groundwater exploitation was seepage water from the clay soil. Therefore, the estimation results of groundwater exploitation differed significantly. Through the study on the samples within the exploitation depth in North China, the relationship between water seepage amount and deformation of soil has been analyzed to provide the basis for further understanding the mechanism of land subsidence and reasonable assessment of deep groundwater exploitation.

\section{Sources, handling and set-up of soil samples}

The samples have been taken from the fringe regions of typical depression cone of groundwater exploitation in North China: Huanghua and Hengshui areas, from the drilling core within $600 \mathrm{~m}$ depth. The lithology is mainly clay soil, with a small amount of sandy soil contained.

The mud wall-protection and rotary drilling method with a double-tube rotary soil sampler was used to collect all the samples. The outside diameter of the core tube was $108 \mathrm{~m}$. To collect medium or coarse sands, a double-action and triple-pipe rotary soil sampler was used. To collect fine sands or clay soils, a single-action and triple-pipe rotary soil sampler was used. Grade I crude samples were collected according to the National Standard of Geotechnical Engineering (GB50021-2001).

The soil sample is saturated. Shallow groundwater table in the researched area is about $3.0 \mathrm{~m}$ below the ground surface and the natural soilmass is all saturated. For the sample being saturated well, a set of vacuum pumping system was made, which was composed of sample device, vacuum pump, thermocouple vacuum gauge and cooling system. The main process was shown in Fig. 1. According to the numerical values shown by the thermocouple vacuum gauge, sealing of the device was adjusted to maintain a good vacuum state. Based on the sample viscosity level, the air extraction time was normally controlled within 6-8 h. Subsequently, the water inlet valve was opened and the air was pumped slowly while the distilled water was injected. After the water sample was submerged and there were no air bubbles in the distilled water, pumping was continued for approximately $1 \mathrm{~h}$ before being stopped. The air valve of the saturation device was opened, so that the atmospheric pressure was inversely added to the sample and the sample was saturated in water for more than $24 \mathrm{~h}$. According to calculation results, the saturation of treated samples could reach $88.2-100.0 \%$.

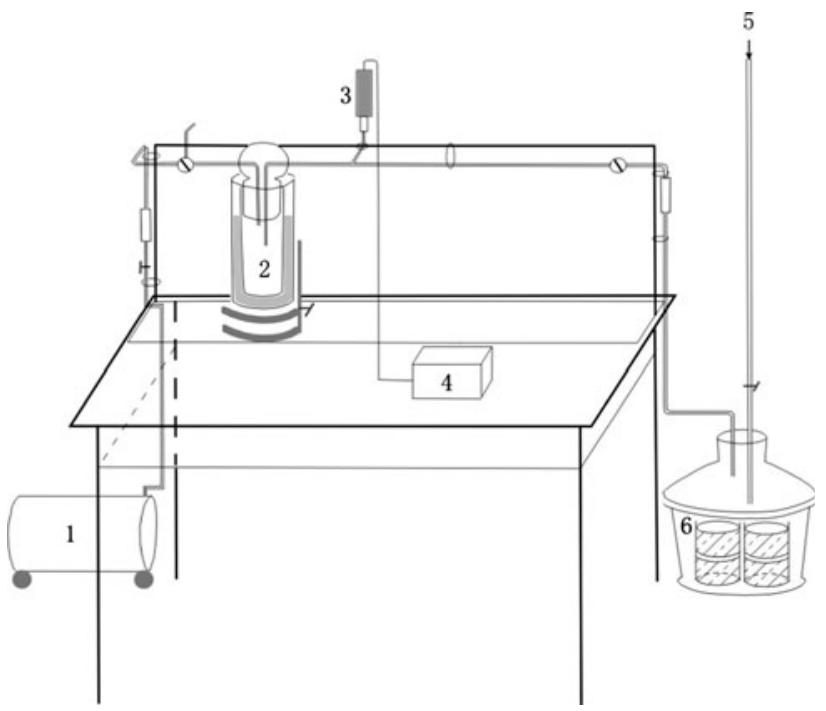

Fig. 1 Schematic diagram of samples-vacuum pumping. 1 Vacuum pump; 2 Liquid-nitrogen-cooled device; 3 Thermal couple pipe; 4 Vacuum measurement; 5 Distilled water; 6 Soil sample

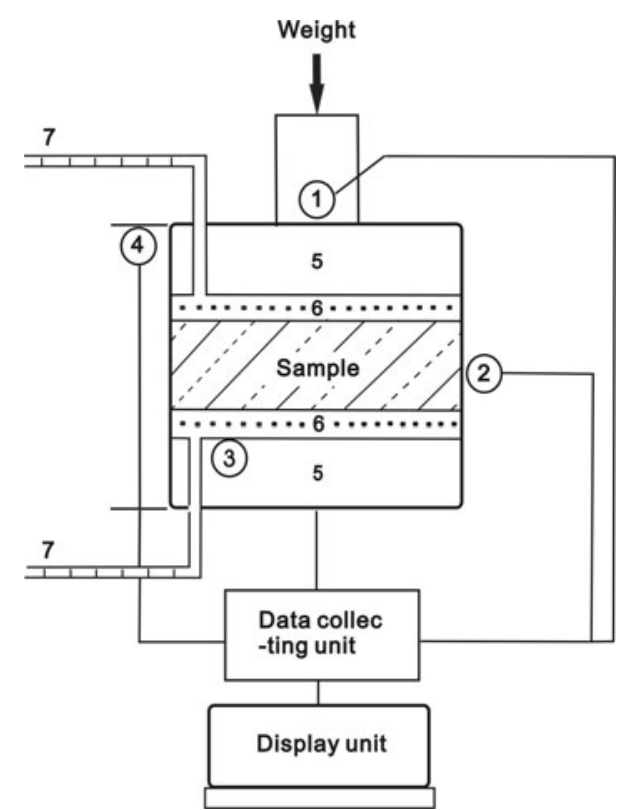

Fig. 2 Schematic diagram of multi-function consolidometer. 1 Vertical stress sensor; 2 Laterral stress sensor; 3 Seepage pressure sensor; 4 Dispacement sensor; 5 Sealed stopper; 6 Pervious stone; 7 Reading unit of realeased proe water

The experimental principle is basically equivalent to that of compression test and the characteristics mainly lie in the following two points. First, the maximum stress is large, reaching $20 \mathrm{MPa}$. The self-weight stress of sample is larger than $6 \mathrm{MPa}$ and the maximum depth of samples is approximately $600 \mathrm{~m}$; thus, the ordinary consolidation test instrument (3.2 or $4.0 \mathrm{MPa}$ ) cannot meet the requirements. The test apparatus is a specially designed multi-functional 
high-pressure consolidation joint-penetration tester, which is mainly composed of the sample chamber, pressure system, sensor value system, storage and display system. The equipment is shown in Fig. 2. The sample area was $30 \mathrm{~cm}^{2}$, and the height was $4.0 \mathrm{~cm}$. The criterion of stability of soil deformation is not larger than $0.005 \mathrm{~mm} / \mathrm{h}$ (higher precision than the deformation criterion of no more than $0.01 \mathrm{~mm} / \mathrm{h}$ prescribed in National Criterion of Geotechnical Test), and the next test can be carried out. Secondly, more parameters can be obtained than the usual compression test. In the process of compression test, the parameters such as vertical stress, deformation, lateral stress, pressure and amount of water seepage can be obtained. Except the seepage water that was recorded manually (recorded by the monitor), the rest parameters were automatically recorded.

The analysis of deformation data of soilmass under the self-weight $+0.8 \mathrm{MPa}$ stress has particularly been conducted in consideration of the fact that groundwater table in the majority of the central areas of groundwater exploitation has declined by $50 \mathrm{~m}$ since 1960, and that groundwater table fluctuates within the range of $20.0 \mathrm{~m}$ during the dry and wet seasons over years in the study area, It was also presumed that every $10 \mathrm{~m}$ declining of groundwater table was equivalent to $100 \mathrm{kPa}$ superimposed stress on the soilmass.

\section{Analysis of test results}

The results showed that under the same stress, the lateral stress, deformation and seepage water were gradually increased with time, while the penetration rate was reduced until it was stablilized. With continuous increase of stress, the lateral stress, deformation and seepage water were also increased, while the penetration rate decreases, but within the same order of magnitude. Change of each parameter was shown in Fig. 3.

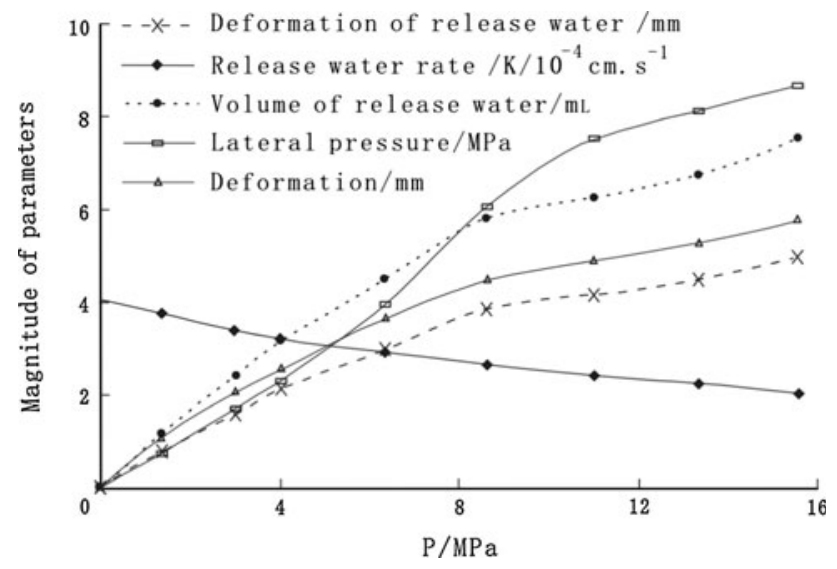

Fig. 3 Change curve of indices of soilmass properties with stress
The characteristics of seepage water under the stress

The total water amount in the soil can be calculated according to the basic formula of the density and soil mass. Soil density can be calculated by the formula: $\rho=m / v$. Soil total mass can be calculated by the formula: $m=m_{\mathrm{s}}+m_{\omega}$, water content can be calculated by the formula: $\omega=m_{\omega} / m_{\mathrm{s}}$ and the weight of water in the soil can be calculated by the formula: $m_{\omega}=\rho v \omega /(1+\omega)$, where $\rho$ represents wet density $\left(\mathrm{g} / \mathrm{cm}^{3}\right), m$ represents total mass of the soil $(\mathrm{g}), m_{\mathrm{s}}$ represents mass of soil particles $(\mathrm{g}), v$ represents sample volume $\left(\mathrm{g} / \mathrm{cm}^{3}\right)$ and $\omega$ represents water content $(\%)$. The seepage water from samples was measured in the process of compression test.

Test samples included clay, silty clay, silt and sand. The results showed that with the gradual increase of stress, clay had the highest amount of seepage water, followed by sandy soil. Calcareous cemented sand had the lowest amount of seepage water.

These results also showed that under the stress of 3-4 times self-weight $\left(P_{0}\right)$, seepage water from soil sample accounts for $4.25-23.43 \%$ of total water in the soil. Under $P_{0}+0.8 \mathrm{MPa}$ stress, after the deformation of soil, seepage water from soil sample accounted for $1.48-10.84 \%$ of total water in the soil and $0.625-4.534 \%$ of the soil sample volume with an average of $1.954 \%$. The average seepage water was from clay, silty clay and sandy soil for 2.050, $1.975,1.700 \%$ of total samples volume, respectively. Clay had the highest amount of seepage water and deformation, followed by the silt and calcareous highly cemented clay soil. Sandy soil had the lowest amount of seepage water and deformation.

There was more seepage water from the clay than that from silty sand, which was possibly due to the fact that with the increases of stress, effective stress was first undertaken by the seepage in the soils and then gradually transmitted to the soil particles. Because the majority of the seepage from clay was weakly bound water, there was a certain amount of adhesion (plasticity) between the particles. The speed that the effective stress was transmitted to the clay particles was extremely slow and during this process a lot of seepage (weakly bound water) was gradually transformed into gravitational water, which produced high deformations and released a large amount of water. In contrast, the adhesion for the particles of sandy soils was small. The effective stress that was undertaken by the seepage was very short and was transmitted to the sandy soil particles quickly, which resulted in small deformations of sandy soil. Therefore, there was a small amount of seepage water released from the sandy soil.

The amount of the water released was mainly related to the property of soil. The soils that released a high amount of water were clay soil with high plasticity index, high 


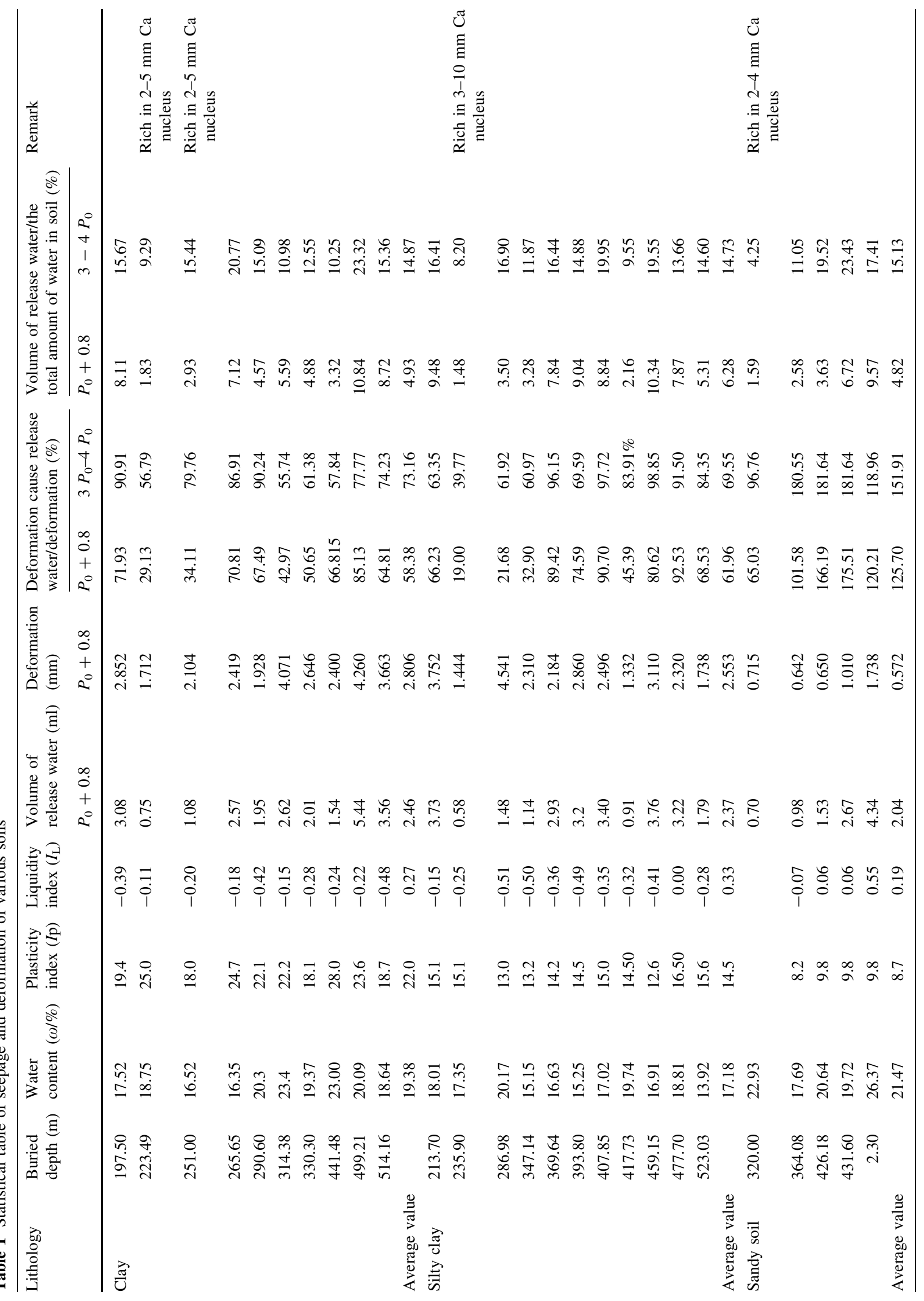


liquid index and without nuclear calcium. In this study, the samples with a plasticity index of 23.6, 9.8, 12.6 and 15.1 contained $5.44,4.34,3.76$ and $3.73 \%$ seepage water, respectively. Seepage water in the soil with different properties and deformation parameters was shown in Table 1. In addition, the deformation occurred after the stress, and the water release occurred after the deformation.

Relationship between seepage deformation and actual deformation under the stress

To compare the actual deformation and the seepage deformation of the soilmass, seepage water from the soil sample was divided by the volume of sample and was converted into actual deformation of the sample.

The results showed that $85 \%$ of the samples had less seepage deformation compared to the actual deformation. Under effective stress as 3-4 times of $P_{0}$, the seepage deformation and actual deformation ranged between 181.64 and $39.77 \%$, with an average of $89.77 \%$. Under the stress of self-weight $P_{0}+0.8(\mathrm{MPa})$, the seepage deformation was $175.51-19.00 \%$ of the actual deformation, with an average of $72.84 \%$. However, there were some differences between test results of clay soil and those of sandy soil.

The actual deformation was higher than seepage deformation in clay soil. The largest deformation occurred in the silty clay and clay, with a plasticity index $I_{\mathrm{P}}$ of $13.0,15.1$, 18.7, 22.2 and 23.6 for each individual sample. Clay soil had the greatest glutinosity. Under 3-4 times of the selfweight stress, the seepage deformation was $98.85-39.77 \%$ of the actual deformation, with an average of $71.27 \%$. The seepage deformation being close to the actual deformation occurred in approximately $28.6 \%$ of clay soil. Under the stress of self-weight stress $P_{0}+0.8$ (Mpa), the seepage deformation was $92.53-19.00 \%$ of the actual deformation, with an average of $60.26 \%$. Soil seepage deformation being close to actual deformation occurred in only $14.3 \%$ of clay and all of such soils were silty clay.

The seepage deformation of silty soil and sandy soil was larger than their actual deformation. The seepage deformation was $96.76-181.64 \%$ of the actual deformation under 3-4 times of the self-weight stress $\left(P_{0}\right)$. The seepage deformation was $65.03-120.21 \%$ of the actual deformation under the stress of self-weight stress $P_{0}+0.8(\mathrm{MPa})$.

Although there were differences between the seepage deformation of various soils and the actual deformation, the trend of the changes for the seepage water deformation and actual deformation were identical, with the former being smaller than the latter. The relationship among the stress, actual deformation and seepage deformation was logarithmic curve formula. The relationship between the stress and the deformation can be calculated by the formula: $\ln P=A \ln S-B$, where $P$ was the stress, $S$ was the deformation or the seepage deformation of sample, $A$ and $B$ were constant $\left(0.908756 \leq R^{2} \leq 1,0.006432 \leq\right.$ residual mean square $\leq 0.042995)$.

The characteristic of curve change was shown in Fig. 3. Seepage and deformation parameters of different types of soils were shown in Table 1.

Exhaust

In the process of the compression test, the samples requiring exhaust accounted for $20 \%$ of total samples, and most of these samples were clay. In the process of compression test under stress greater than self-weight stress, the samples observed with gas accounted for $18.3 \%$ of the total samples. Samples with air exhaust accounted for $11.54 \%$ of the total samples under $P_{0}+0.8(\mathrm{MPa})$ stress, and the rest were observed with air exhaust under the stress of $P_{0}+0.8$ (MPa). Artificial reading was used for seepage water. Gas exhaust and seepage were monitored in the same device connected with the atmosphere. It cannot be ensured that all gas exhausted can be detected as the gas exhaust was an instantaneous process. Therefore, the actual number of samples with gas exhaust and air exhaust were higher than the recorded number. Gas exhaust was not analyzed quantitatively.

Relationship between the rebound of soilmass unloading deformation and that of the soilmass loading deformation

To control the disasters caused by groundwater exploitation, the groundwater exploitation was reduced and the water level increased to achieve the purpose of recovering depression cone step by step. Similarly, repeated loading and unloading tests on the samples from the research area were carried out under the stress of $P_{0}+0.2(\mathrm{MPa}) \sim$ $P_{0}+0.8(\mathrm{MPa})$ in consideration of the groundwater environment in this area.

In the process of unloading, the decrease of effective stress, lateral pressure and pore water pressure of soilmass resulted in water absorption and rebound. The results showed little rebound. The rebound deformation with an average of $13.97 \%$ accounted for $4.73-37.61 \%$ of the total deformation. The rebound deformation caused by water absorption accounted for $32.23-65.37 \%$ of the actual rebound.

The fact that the rebound is less than compression was due to two major factors. First, the geological area where the soilmass was located affected the rebound of soilmass. In other words, the generation age and genesis of soilmass were the main factors. Comparison was also conducted on samples with similar depth from two regions. It was found 
that there was no significant difference among the rebound indices of the soilmass in the same area, except for a few samples. However, the rebound indices of two areas differed with each other by several times. Generally speaking, the compression was smaller and rebound index was greater on the condition of longer soilmass formation, greater buried depth, higher content and hardness of calcium. Secondly, the liquid index $I_{\mathrm{L}}$ was another index affecting the soilmass rebound. The plasticity indices $\left(I_{\mathrm{p}}\right)$ in two regions were similar, although the liquid indices $\left(I_{\mathrm{L}}\right)$ are different, with the average values of 0.02 and 0.26 , respectively, for the two regions. In the areas where there were mainly hard plasticity soils $\left(0<I_{\mathrm{L}} \leq 0.25\right)$, the rebound index was significantly smaller than that of hard soilmass $\left(I_{\mathrm{L}} \leq 0\right)$. Changing characteristics of soilmass parameters in different areas were shown in Fig. 4.

\section{Discussion and analysis}

From the viewpoint of law of the matter conservation, the actual deformation of soilmass should be equivalent to the seepage deformation under the stress. These results showed that the actual deformation of clay and silty clay was greater than the seepage deformation under the stress, while the actual deformation of silt and sandy soil was less than the seepage deformation. Statistical overview was shown in Table 1.

The actual deformations of the clay and silty clay were greater than the seepage deformations under the stress no $<3-4$ times of self- weight. This was mainly due to the following reasons. First, the closed gas exhausts through pore water with the increase of effective stress, and the exhausted gas also accounts for the deformation. Secondly, the stress acts on the soil samples. On the one hand, a part of bound water can be released from the clay soil only by converting into free water. The distance between soil particles is relatively reduced, and the soil particles absorb pore water more strongly, which results in a lag for the outflow of pore water (Brandes et al. 1996; Kayadelen 2008). At the same time, the soil particles with high intensity squeeze into the soil particles with low intensity, leading to the soilmass deform without release of pore water. Thirdly, a small amount of soil particles outflow. In this study, a small amount of soil particles was released with pore water, contributing to soilmass deformation. These results suggest that some sandy soil particles were drawn out in the process of groundwater exploitation. Finally, a small amount of water moisture evaporates during the tests. In the experiment, the temperature was controlled at $20-25^{\circ} \mathrm{C}$, and the relative humidity of ambient air around the water seepage pipes was controlled at about $80 \%$. However, there was still evaporation of water moisture.

The seepage deformation of the silty soil and sandy soil is greater than the actual deformation. The compression modulus of the sandy soil (sand, silty sand) is so large that the stress transfers instantaneously among the sand particles and the deformation occurs instantaneously with the increasing stress. Compared with the clayey soil, the porosity of saturated sand is relatively large, the pore connectivity is good, and free water content is relatively high. The movement of free water depends mainly on the self-gravity; thus, it also flows even with the absence of stress. In fact, the sandy soil is the water-bearing layer. Therefore, free water has close link to the lateral and vertical recharge, and the degree of water-releasing reflects the recharge characteristics of sandy soil.

The results show that with the increases of effective stresses, the released water amount of silty clay is the highest, followed by clay. The released water amount of sandy soil is the lowest. Under the self-weight $P_{0}+0.8$ (MPa) stress, the deformation of clay is the largest, followed by silty clay, silt and sand soil. The order of deformation is clay $>$ silty clay $>$ silt $>$ sandy soil. The ratio of seepage deformation and actual deformation is on
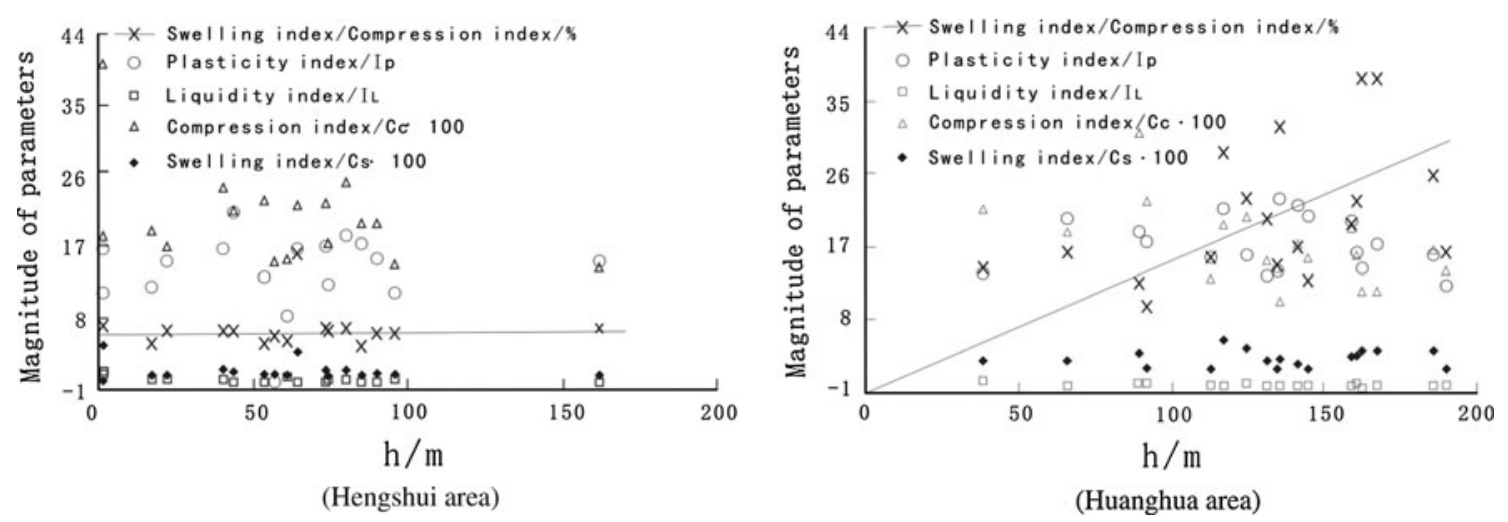

Fig. 4 Changing characteristics of soilmass parameters with depth in different areas 
the contrary, and the order is sand $>$ silt $>$ silty clay $>$ clay. Less water is released when cementation of soil calcium becomes stronger.

The rebound of the studied soilmass (including clayey soil and sandy soil) is small, and the average ratio between the rebound and deformation is $13.97 \%$. Compared with clay soil, the rebound of sandy soil is very small without complete flexibility. In other words, the sandy soil also possesses the characteristic of creep and the velocity of deformation and rebound is faster than that of the clayey soil. These results are similar to previous studies (Mikhalyuk and Zakharov 2000; Dezhina 2005; Liu et al. 2004; Miao et al. 2002; Van Camp and Walraevens 2009; Prisco et al. 2000; Shi et al. 2008; Sivakumar et al. 2001). However, these results are different from traditional viewpoint that the sandy soil is elastic (Shearer 1998; Ortega-Guerrero et al. 1999). This needs to be further studied in the future.

\section{Conclusion}

The following conclusions can be obtained through the study of deformation and seepage in different types of soils in North China.

1. The deformation amount of soilmass is not equal to the amount of water seepage from the soilmass. Under the $P_{0}+0.8$ (MPa) stress, the deformation induced by seepage of most clay soils is about $60 \%$ of the actual deformation. Seepage deformation being similar to actual deformation occurs to only about $14.3 \%$ of silty clay. As to sandy soil, the seepage deformation is about $125 \%$ of the actual deformation. However, the seepage ability of soilmass is on the contrary, and the order of ratios of seepage deformation and actual deformation is sand and silt $>$ silty clay $>$ clay.

2. As the stress increases, the clay soil may deform to the greatest extent. The soilmass deformation is related to consistency and hardness of soilmass. Under a certain stress, the deformations of different kinds of soils are in the following order: clay $>$ silty clay $>$ silt $>$ sandy soil. Under the same consistent condition, soft soil produces more deformations. The amount of water seepage from soilmass is also related to the soil consistency and hardness. The soft soil with bigger plasticity index releases more water.

3. It is found that a certain amount of gas releases with pore water in the process of monitoring water seepage.

4. The rebound of soil depends on the historical characteristics of soil genesis and the plastic state of soil structure.
5. The sandy soil in these two areas of North China does not possess the complete flexibility characteristics under stress. The rebound is $4.73-37.61 \%$ of the deformation, with an average of $13.97 \%$.

Acknowledgments This research was financially supported by the projects of National Natural Science Foundation (No.: 40472139), Institute of Hydrogeology and Environmental Geology, Chinese Academy of Geological Sciences (Sk07006 and Sk07017), National Basic Research Program of China (No: 2010CB428803), Environmental Geological Survey in major urban Environmental (No.:1212010540400) and Shijiazhuang Bureau of Science and Technology (No.:121383A).

Open Access This article is distributed under the terms of the Creative Commons Attribution Noncommercial License which permits any noncommercial use, distribution, and reproduction in any medium, provided the original author(s) and source are credited.

\section{References}

Brandes HG, Silva AJ, Ag A, Veyera GE (1996) Consolidation and permeability characteristics of high-porosity surficial sediments in Eckernförde Bay. Geo-Mar Lett 16:175-181

Dezhina IY (2005) Deformation analysis of loess foundation bed with allowance for elastoplastic properties of the soil. Soil Mech Found Eng 42(1):9-14

Gallardo AH, Marui A, Takeda S, Okuda F (2009) Groundwater supply under land subsidence constrains in the Nobi Plain. Geosci J 13(2):151-159

Hu RL (2004) Review on current status and challenging issue of land subsidence in China. Eng Geol 76:65-77

Kayadelen C (2008) The consolidation characteristics of an unsaturated compacted soil. Environ Geol 54(2):325-334

Liu CH, Pan YW, Liao JJ, Huang WT (2004) Estimating coefficients of volume compressibility from compression of strata and piezometric changes in a multiaquifer system in west Taiwan. Eng Geol 75:33-47

Miao L, Liu S, Lai Y (2002) Research of soil-water characteristics and shear strength features of Nanyang expansive soil. Eng Geol 65:261-267

Mikhalyuk AV, Zakharov VV (2000) Deformation aftereffect in soils and rocks under dynamic loads. J Min Sci 36(2):141-148

Ortega-Guerrero A, Rudolph DL, Cherry JA (1999) Analysis of longterm land subsidence near Mexico City: field investigations and predictive modeling. Water Resour Res 35(11)3327-3341

Prisco CD, Imposimato S, Vardoulakis I (2000) Mechanical modeling of drained creep triaxial tests on loose sand. Geotechnique 50(1):73-82

Shearer TR (1998) A numerical model to calculate land subsidence, applied at Hangu in China. Eng Geol 49(2):85-93

Shi X, Xue Y, Wu J, Ye S, Zhang Y (2008) Characterization of regional land subsidence in Yangtze Delta, China: the example of $\mathrm{Su}-\mathrm{Xi}-\mathrm{Ch}$ ang area and the city of Shanghai. Hydrogeol J 16(3):593-607

Sivakumar V, Doran IG, Graham J, Johnson A (2001) The effect of anisotropic elasticity on the yielding characteristics of overconsolidated natural clay. Can Geotech J 38(1):125-137

Van Camp M, Walraevens K (2009) Recovery scenarios for deep over-exploited aquifers with limited recharge: methodology and application to an aquifer in Belgium. Environ Geol $56: 1505-1516$ 